Bài báo khoa học

\title{
Tính toán một số đồng lợi ích của các kịch bản giảm phát thải khí nhà kính trong giao thồng vận tải hành khách trên nền số liệu quy hoạch phát triển giao thông vận tải của Thủ đô Hà Nội và thành phố Hồ Chí Minh
}

\author{
Trần Đỗ Bảo Trung ${ }^{1 *}$, Lương Quang $\mathrm{Huy}^{1}$, Trần Đỗ Trà $\mathrm{My}^{2}$ \\ ${ }^{1}$ Cục Biến đổi khí hậu, Bộ Tài nguyên và Môi trường; tdbtrung@ monre.gov.vn; \\ huylq98@gmail.com \\ ${ }^{2}$ Quỹ Bảo vệ môi trường Việt Nam, Bộ Tài nguyên và Môi trường; \\ mytranvepf@gmail.com \\ * Tác giả liên hệ: tdbtrung@monre.gov.vn; Tel: +84-904620310
}

Ban Biên tập nhận bài: 12/8/2020; Ngày phản biện xong: 15/09/2020; Ngày đăng:25/10/2020

Tóm tắt: Nghiên cứu này áp dụng phương pháp lượng giá đồng lợi ích để tính toán giá trị 2 đồng lợi ích: tiết kiệm năng lượng và bán tín chỉ các-bon cho các kịch bản giảm phát thải khí nhà kính trong lĩnh vực giao thông vận tải hành khách trên nền số liệu quy hoạch phát triển giao thông vận tải của Thủ đô Hà Nội và thành phố Hồ Chí Minh. Việc tính toán đã được thực hiện cho 7 kịch bản giảm phát thải khí nhà kính khác nhau. Kết quả nghiên cứu đạt được cho phép chỉ ra một cách định lượng tính hiệu quả của từng kịch bản giảm phát thải khí nhà kính về tiết kiệm năng lượng, tiềm năng bán tín chỉ các-bon. Trong đó, giá trị hiện tại ròng tại năm 2020 của 2 đồng lợi ích đạt đến con số 22.056,08 tỷ VNĐ ở Thủ đô Hà Nội theo kịch bản 03 và 11.609,20 tỷ VNĐ ở thành phố Hồ Chí Minh theo kịch bản 05 .

Từ khóa: Đồng lợi ích; Giảm phát thải khí nhà kính; Giao thông vận tải hành khách; Thủ đô Hà Nội; Thành phố Hồ Chí Minh.

\section{1. Đặt vấn đề}

Biến đổi khí hậu hiện là một vấn đề cấp bách của toàn xã hội khi các tác động tiêu cực của nó ngày càng trở nên rõ ràng và nghiêm trọng. Để giải quyết vấn đề này, 185/197 quốc gia thành viên của Công ước khung của Liên hợp quốc về Biến đổi khí hậu (UNFCCC), trong đó có Việt Nam, đã phê chuẩn Thỏa thuận Paris về biến đổi khí hậu. Mục tiêu chính của Thỏa thuận này là tăng cường các nỗ lực toàn cầu để giữ nhiệt độ trung bình của Trái đất trong thế kỷ 21 tăng không quá $2^{\circ} \mathrm{C}$ so với thời kỳ tiền công nghiệp, hướng tới phát triển một tương lai các-bon thấp và bền vững [1]. Để thực hiện mục tiêu đã đặt ra, khái niệm đồng lợi ích đã được nhiều chuyên gia kinh tế và nhà hoạch định chính sách nhấn mạnh trong quá trình triển khai các giải pháp giảm phát thải khí nhà kính. Theo Báo cáo Đánh giá lần thứ 5 , Ủy ban Liên chính phủ về Biến đổi khí hậu (IPCC), các giải pháp giảm phát thải khí nhà kính sẽ không chỉ làm giảm tác động tiêu cực của biến đổi khí hậu mà còn đem lại những lợi ích khác về môi trường, xã hội [2]. Các chính sách biến đổi khí hậu thường đem lại các lợi ích chỉ có thể xác định trong tương lai sau này, trong khi đó, các chi phí mang tính tức thời và có khối lượng lớn. Khái niệm đồng lợi ích cho phép xác định các lợi ích tức thời, trực tiếp tại địa điểm áp 
dụng giải pháp giảm phát thải khí nhà kính, từ đó, tạo cơ sở cho các khoản đầu tư về ứng phó với biến đổi khí hậu.

Hiện nay, một số các đồng lợi ích trong lĩnh vực giao thông vận tải hành khách đã được nghiên cứu. Kết quả nghiên cứu thường được đưa ra ở dạng định tính, định lượng, tuy nhiên, số lượng các nghiên cứu thực hiện định lượng giá trị tiền tệ hiện còn hạn chế. Một số đồng lợi ích trong lĩnh vực giao thông vận tải nói chung, vận tải hành khách nói riêng đã được thực hiện bao gồm: ô nhiễm tiếng ồn; tiết kiệm năng lượng; giảm tỷ lệ tai nạn giao thông; giảm ùn tắc giao thông.

Hướng tiếp cận đồng lợi ích trong các giải pháp giảm phát thải khí nhà kính vẫn còn là một vấn đề mới tại Việt Nam. Đặc biệt, trong lĩnh vực giao thông vận tải hành khách, số lượng nghiên cứu về phương pháp và quy trình lượng giá các đồng lợi ích từ các giải pháp giảm phát thải khí nhà kính còn hạn chế. Tác giả xây dựng quy hoạch giao thông vận tải của Thủ đô Hà Nội và thành phố Hồ Chí Minh đã sử dụng các phương pháp phân tích chi phí hiệu quả, phân tích chi phí-lợi ích để đánh giá hiệu quả các dự án thành phần thuộc quy hoạch (các dự án BRT, các dự án đường sắt đô thị, ...). Tuy nhiên, cũng cần nói rõ ở đây rằng: trong các báo cáo nghiên cứu khả thi của các dự án đã xem xét, người ta chỉ đạt đến việc nêu ra các lợi ích xã hội và môi trường một cách định tính hoặc bán định lượng. Điều này ít nhiều làm giảm đi tính thuyết phục của dự án. Các lợi ích về biến đổi khí hậu cũng chưa được đề cập trong các báo cáo dạng này. Vì vậy, cần có nghiên cứu để lượng giá cụ thể các đồng lợi ích này, cung cấp một góc nhìn tổng thể hơn khi đánh giá hiệu quả triển khai các giải pháp giảm nhẹ phát thải khí nhà kính trong quy hoạch phát triển giao thông vận tải của Thủ đô Hà Nội và thành phố Hồ Chí Minh.

Phương pháp lượng giá đồng lợi ích là một phương pháp khá mới, đang được sử dụng một cách rộng rãi trên phạm vi toàn thế giới nhằm đánh giá hiệu quả các giải pháp giảm phát thải khí nhà kính trong lĩnh vực biến đổi khí hậu. Phương pháp này cũng đã được một số nhà khoa học Việt Nam áp dụng thành công khi nghiên cứu về giảm phát thải khí nhà kính trong lĩnh vực quản lý chất thải [3-4]. Nghiên cứu này sẽ áp dụng phương pháp lượng giá đồng lợi ích để tính toán giá trị 2 đồng lợi ích: tiết kiệm năng lượng và bán tín chỉ các-bon cho các kịch bản giảm phát thải khí nhà kính trong lĩnh vực giao thông vận tải hành khách trên nền số liệu quy hoạch phát triển giao thông vận tải của Thủ đô Hà Nội và thành phố Hồ Chí Minh. Kết quả nghiên cứu đạt được cho phép chỉ ra một cách định lượng tính hiệu quả của từng kịch bản giảm phát thải khí nhà kính.

\section{Phương pháp nghiên cứu}

\subsection{Giới thiệu khu vục nghiên cưu}

\subsubsection{Thủ đô Hà Nội}

Năm 2020, Thủ đô Hà Nội là một thành phố lớn thứ hai trong 76 đô thị của Việt Nam, diện tích $3.359 \mathrm{~km}^{2}$, dân số đạt 8.053 .663 người. Chính quyền và nhân dân Thủ đô Hà Nội cũng đang phải đối mặt với nhiều thách thức trong quá trình phát triển. Một trong những thách thức lớn mà nhiều người gọi đó là thảm họa là sự ách tắc giao thông diễn ra thường xuyên, liên tục trên hệ thống giao thông vận tải vốn chưa thực sự phát triển cả về cơ sở hạ tầng, phương tiện, ý thức tuân thủ luật giao thông. Năm 2020, mạng lưới giao thông đường bộ của Thủ đô Hà Nội mới chỉ đạt $9 \%$ quỹ đất thành phố. Đây là một con số rất nhỏ so với các đô thị phát triển trên thế giới-con số này đạt 20-22\% (Seoul: 20\%; London: $23 \%$ và New York: $22 \%)$. Giao thông tĩnh của Hà Nội chỉ đạt trên $1 \%$ quỹ đất của thành phố, con số này cần thiết đạt mức 4-6\% quỹ đất của thành phố.

Đến năm 2020, tại Hà Nội, tổng số phương tiện vận chuyển hành khách cá nhân vẫn chiếm ở mức rất cao: $86 \%$. Vận tải hành khách bằng phương tiện công cộng vẫn chủ yếu bằng xe buýt, taxi với tốc độ lưu thông rất chậm $15-18 \mathrm{~km} / \mathrm{h}$. Tỷ lẹ̣ hành khách đi xe buýt chỉ đạt 
mức $13 \%$ của tổng số hành khách. Tuyến xe buýt nhanh Kim Mã-Lê Văn Lương-Yên Nghĩa đã được đưa vào hoạt động từ năm 2018 nhưng năng lực vận chuyển toàn tuyến chỉ đạt $50 \%$ công suất kỳ vọng. Về đường sắt đô thị, tuyến số $2 \mathrm{~A}$ (Tuyến Cát Linh): Cát Linh-Hà Đông, và tuyến số 3 (Tuyến Văn Miếu), đoạn Nhổn-Ga Hà Nội là hai tuyến đường sắt đầu tiên được xây dựng. Quá trình xây dựng các tuyến đường sắt hiện đang chậm tiến độ và bị đội vốn rất nhiều do quá trình xây dựng kéo dài. Tuyến số $2 \mathrm{~A}$ đã có 8 lần lỡ tiến độ hoàn thành và đến nay (tháng 7 năm 2020) vẫn chưa xác định được chính xác thời điểm đi vào khai thác thương mại. Tuyến số 3 đoạn Nhổn-Ga Hà Nội cũng đã phải điều chỉnh tiến độ 2 lần và dự kiến sẽ khai thác thương mại toàn tuyến vào cuối năm 2022. Có thể mô tả một cách tổng quát là hệ thống vận tải hành khách của Thủ đô Hà Nội còn nhiều khiếm khuyết và vì thế nó chưa có vai trò tương xứng với một thành phố có quy mô lớn đang trên đà phát triển.

\subsubsection{Thành phố Hồ Chí Minh}

Thành phố Hồ Chí Minh là đô thị lớn nhất Việt Nam. Diện tích của thành phố là $2.061 \mathrm{~km} 2$, dân số 8.993 .082 người vào năm 2019. Về giao thông vận tải, thành phố Hồ Chí Minh cũng đang gặp nhiều vấn đề của một đô thị đang phát triển với tốc độ nhanh. Cơ sở hạ tầng giao thông vận tải còn ở mức chậm phát triển. Các loại hình phương tiện giao thông vận tải cũng mới chỉ gồm: xe đạp, xe máy, xe ô tô cá nhân, taxi, xe buýt. Các loại hình phương tiện giao thông công cộng có sức chở lớn vẫn chỉ có trong quy hoạch. Trên thực tế, 3 năm gần đây, thành phố Hồ Chí Minh đã xây dựng xong một số tuyến xe buýt nhanh, nhưng hoạt động của nó chưa đáp ứng được kỳ vọng. Tỷ lệ giao thông vận tải hành khách của thành phố Hồ Chí Minh bằng phương tiện cá nhân vẫn chiếm tới $86 \%$ vào năm 2020 . Các tuyến đường sắt đô thị đã khởi công xây dựng trên địa bàn thành phố cũng bị chậm tiến độ, nhiều lần điều chỉnh vốn. Đến nay, chưa tuyến nào bắt đầu hoạt động thương mại.

Cũng giống như Thủ đô Hà Nội, thành phố Hồ Chí Minh đang gặp những bất cập trong lĩnh vực giao thông vận tải: kẹt xe thường xuyên, liên tục; tốc độ lưu chuyển của các phương tiện giao thông chỉ đạt $15-18 \mathrm{~km} / \mathrm{h}$; an toàn giao thông vẫn không đạt chỉ tiêu đặt ra; ý thức tham gia giao thông của cộng đồng dân cư có được cải thiện nhưng chưa thật sự cao. Trong những năm gần đây, do biến đổi khí hậu diễn ra mạnh mẽ ở khu vực Đông Nam Bộ, thành phố Hồ Chí Minh có thêm một vấn nạn trong hoạt động giao thông vận tải đó là hiện tượng triều cường gây ngập có khi tới $1 / 3$ diện tích thành phố. Điều này gây trở ngại lớn cho cộng đồng dân cư ở đây.

\subsection{Phương pháp lượng giá đồng lợi ich}

Khái niệm lượng giá đồng lợi ích dự án đã được sớm đề cập đến trong các nghiên cứu từ năm 1986 [5-7]. Mỗi một dự án đều thể hiện tác động của con người vào thế giới tự nhiên và xã hội nhằm đạt một hoặc một số mục tiêu nhất định. Người ta gọi đó là mục tiêu chính của dự án. Với Phương pháp phân tích chi phí-lợi ích (CBA) chú trọng đến việc tính toán lợi ích ròng khi đạt được mục tiêu chính. Lợi ích ròng này cũng có thể gọi là lợi ích ròng chính. Trong thực tế, khi thực hiện một dự án nào đó, ngoài mục tiêu chính, nhiều khi người ta cũng đạt được các mục tiêu khác đi kèm. Chúng ta gọi các mục tiêu đi kèm này là các mục tiêu phụ. Hiển nhiên là, việc đạt được các mục tiêu phụ cũng sẽ cho phép tạo ra các lợi ích ròng phụ. Với lập luận này, công thức tính lợi nhuận của một dự án có thể được viết lại như sau:

$$
P=P_{C}+P_{P}=(B-C)+P_{P}
$$

Trong đó $\mathrm{P}$ là lợi nhuận ròng tổng hợp của dự án; $\mathrm{P}_{\mathrm{c}}$ là lợi nhuận ròng chính của dự án; $\mathrm{P}_{\mathrm{p}}$ là lợi nhuận ròng phụ của dự án; $\mathrm{B}$ là lợi ích ròng của dự án; $\mathrm{C}$ là chi phí ròng của dự án.

Từ diễn giải này đã hình thành phương pháp lượng giá đồng lợi ích dự án. Giá trị lợi nhuận ròng phụ của dự án $(\mathrm{Pp})$ được các tác giả của phương pháp này gọi tên là giá trị các đồng lợi ích. Nhiệm vụ của phương pháp lượng giá đồng lợi ích là tìm cách tính toán các giá trị lợi nhuận ròng phụ của dự án-giá trị các đồng lợi ích Pp. Khi chúng ta thừa nhận diễn giải 
này thì đồng nghĩa chúng ta cũng sẽ xem rằng, phương pháp lượng giá đồng lợi ích là một biến thể mở rộng của phương pháp phân tích chi phí-lợi ích.

Chúng ta sẽ sử dụng hướng tiếp cận dựa vào thị trường nhằm lượng giá 2 loại đồng lợi ích: bán tín chỉ các-bon, tiết kiệm năng lượng. Đây là 2 đồng lợi ích có sự liên quan chặt chẽ đến việc giảm phát thải khí nhà kính trong lĩnh vực giao thông vận tải hành khách nói riêng và biến đổi khí hậu nói chung. Hiện nay, nhiên liệu sử dụng trong lĩnh vực giao thông vận tải hành khách và tín chỉ các-bon là các loại hàng hóa có giá trị trao đổi trực tiếp, được niêm yết trên trên thị trường. Vì vậy, phương pháp tiếp cận dựa vào thị trường sẽ là phương pháp thích hợp để áp dụng lượng giá hai đồng lợi ích này.

\subsection{1 Đồng lợi ích bán tín chỉ các-bon}

Tín chỉ các-bon là giấy phép thể hiện quyền phát thải một tấn $\mathrm{CO}_{2 \text { tợ. }}$ Với mục tiêu tạo ra cơ chế thị trường nhằm khuyến khích phát triển theo hướng phát thải thấp, người ta cho phép các dự án giảm được lượng khí thải nhà kính-đồng nghĩa với việc thu được các tín chỉ các-bon. Lúc đó, trên thị trường thế giới sẽ tồn tại một loại hàng hóa có tên là tín chỉ các-bon. Những nhà đầu tư làm dự án có mức phát thải khí nhà kính cao hơn mức cho phép sẽ phải mua các tín chỉ các-bon từ các nhà đầu tư làm dự án đạt được mức phát thải khí nhà kính thấp hơn mức cho phép. Trong những năm gần đây, giá trị tín chỉ các-bon đang có xu hướng tăng trên thị trường mua bán tín chỉ các-bon này. Đồng lợi ích bán tín chỉ các-bon được tính theo công thức sau:

$$
L_{1}=\Delta \cdot p_{x}=\left(E_{e}-E_{a}\right) \cdot p_{x}
$$

Trong đó $\mathrm{L}_{1}$ là đồng lợi ích từ bán tín chỉ các-bon (VNĐ); $\Delta$ là tiềm năng giảm phát thải khí nhà kính $\left(\Delta=\mathrm{E}_{\mathrm{e}}-\mathrm{E}_{\mathrm{a}}\right)$ (tấn $\mathrm{CO}_{2} \mathrm{t}$ đ); $\mathrm{E}_{\mathrm{a}}$ là lượng phát thải khí nhà kính của kịch bản giả định (tấn $\mathrm{CO}_{2}$ tđ); $\mathrm{E}_{\mathrm{e}}$ là lượng phát thải khí nhà kính của kịch bản cơ sở (tấn $\mathrm{CO}_{2}$ tđ); $\mathrm{p}_{\mathrm{x}}$ là giá bán tín chỉ các-bon ( $\mathrm{VNĐ/tấn} \mathrm{CO}_{2}$ tđ).

\subsection{2 Đồng lợi ích tiết kiệm năng lượng}

So sánh tổng lượng tiêu thụ nhiên liệu của các kịch bản giả định với tổng lượng tiêu thụ của kịch bản cơ sở để tính toán đồng lợi ích về tiết kiệm năng lượng. Công thức tính đồng lợi ích tiết kiệm năng lượng:

$$
L_{2}=\sum_{y=1}^{M}\left(I_{e}-I_{a}\right) \cdot p_{y}
$$

Trong đó $\mathrm{L}_{2}$ là đồng lợi ích từ tiết kiệm năng lượng $(\mathrm{VNĐ})$; $\mathrm{I}_{\mathrm{a}}$ là lượng tiêu thụ nhiên liệu của kịch bản giả định ( $\mathrm{L}$ hoặc $\mathrm{kWh}$ ); $\mathrm{I}_{\mathrm{e}}$ là lượng tiêu thụ nhiên liệu của kịch bản cơ sở ( $\mathrm{L}$ hoặc $\mathrm{kWh}$ ); $\mathrm{p}_{\mathrm{y}}$ là giá bán của nhiên liệu $\mathrm{y}$ (xăng, dầu diesel, điện) (VNĐ/L hoặc $\mathrm{VNĐ/kWh);} \mathrm{y} \mathrm{là}$ loại nhiên liệu $(\mathrm{y}=1,2,3, \ldots, \mathrm{M})$.

\subsection{Thiết lập các kịch bản giảm phát thải khí nhà kính trong lĩnh vụcc giao thông vận tải hành khách tại Thủ đô Hà Nội và thành phố Hồ Chí Minh}

Với các công thức đã được xây dựng, chúng ta sẽ tính toán các đồng lợi ích của các kịch bản giảm phát thải khí nhà kính trong lĩnh vực giao thông vận tải hành khách trên nền số liệu Quy hoạch phát triển giao thông vận tải Thủ đô Hà Nội [8] và thành phố Hồ Chí Minh giai đoạn 2020-2030 [9]. Việc tính toán sẽ được thực hiện cho 7 kịch bản, được lựa chọn theo nguyên tắc: có cơ sở khoa học, có tính khả thi cao, có nhiều khả năng được chính quyền và nhân dân đồng thuận. Nội dung các kịch bản như dưới đây:

- Kịch bản 01 (kịch bản cơ sở): Phát triển giao thông vận tải hành khách Thủ đô Hà Nội và thành phố Hồ Chí Minh theo quy hoạch: Giả định đến năm 2030, các quy hoạch phát triển 
giao thông vận tải sẽ được thực hiện một cách hoàn hảo. Tất cả các chỉ tiêu phục vụ tính toán đều dựa trên số liệu của quy hoạch.

- Kịch bản 02: Giảm tỷ lệ đảm nhận của xe máy, tăng tỷ lệ đảm nhận của giao thông công cộng: Giảm dần tỷ lệ đảm nhận phương tiện của xe máy (mức giảm 3,35\%/năm đối với Thủ đô Hà Nội và 1,925\%/năm đối với thành phố Hồ Chí Minh), tăng hoạt động vận tải hành khách công cộng. Tỷ lệ đảm nhận phương tiện của xe máy vào năm 2030 giảm còn một nửa so với kịch bản cơ sở.

- Kịch bản 03: Giảm tỷ lệ đảm nhận của ô tô cá nhân, tăng tỷ lệ đảm nhận của giao thông công cộng: Từ năm 2020, mồi năm giảm $0,5 \%$ tỷ lệ đảm nhận phương tiện của ô tô cá nhân đối với Thủ đô Hà Nội và $0,192 \%$ đối với thành phố Hồ Chí Minh. Tỷ lệ đảm nhận phương tiện của ô tô cá nhân đến năm 2030 chỉ còn một nửa so với kịch bản cơ sở.

- Kịch bản 04: Giảm mức tiêu thụ nhiên liệu của các loại hình phương tiện: Đề xuất giảm mức tiêu thụ nhiên liệu của các loại phương tiện giao thông vận tải hành khách theo lộ trình giảm $1 \% /$ năm bắt đầu từ năm 2021. Giữ nguyên tỷ lệ đảm nhận phương tiện so với kịch bản cơ sở.

- Kịch bản 05: Tăng tốc độ lưu chuyển phương tiện: Tăng tốc độ lưu chuyển của các phương tiện giao thông vận tải hành khách lên $10 \% /$ năm so với tốc độ hiện nay $(20 \mathrm{~km} / \mathrm{h})$. Với mức tăng này, đến năm 2030, các phương tiện giao thông vận tải hành khách trong thành phố sẽ có thể lưu chuyển với tốc độ trung bình $40 \mathrm{~km} / \mathrm{h}$. Giữ nguyên tỷ lệ đảm nhận phương tiện so với kịch bản cơ sở.

- Kịch bản 06: Tăng hệ số chuyên chở: Giả định hệ số chuyên chở của các loại phương tiện giao thông vận tải hành khách tăng dần mỗi năm $2 \%$ so với hệ số chuyên chở từ năm 2020. Giữ nguyên tỷ lệ đảm nhận phương tiện so với kịch bản cơ sở.

- Kịch bản 07: Sử dụng ô tô điện, xe máy điện: Giả định mỗi năm chuyển $5 \%$ tỷ lệ đảm nhận từ ô tô, xe máy chạy xăng, dầu sang cho ô tô, xe máy chạy điện.

\section{Kết quả nghiên cứu}

\subsection{Tiềm năng giảm phát thải khí nhà kính của các loại phương tiện vận tải hành khách tại Thủ đô Hà Nội và thành phố Hồ Chí Minh}

Kết quả định lượng phát thải khí nhà kính cho các loại phương tiện giao thông vận tải hành khách tại Thủ đô Hà Nội và thành phố Hồ Chí Minh trong giai đoạn 2020-2030 được thể hiện trong Bảng 1 và bảng 2 .

Bảng 1. Lượng phát thải khí nhà kính theo các kịch bản giảm phát thải khí nhà kính trong lĩnh vực giao thông vận tải hành khách tại Thủ đô Hà Nội (triệu tấn CO2tđ).

\begin{tabular}{rrrrrrrrr}
\hline \multirow{2}{*}{ Năm } & $\begin{array}{c}\text { Kịch bản } \\
\text { 01 }\end{array}$ & $\begin{array}{c}\text { Kịch bản } \\
\mathbf{0 2}\end{array}$ & $\begin{array}{c}\text { Kịch bản } \\
\mathbf{0 3}\end{array}$ & $\begin{array}{c}\text { Kịch bản } \\
\mathbf{0 4}\end{array}$ & $\begin{array}{c}\text { Kịch bản } \\
\mathbf{0 5}\end{array}$ & $\begin{array}{c}\text { Kịch bản } \\
\text { Kịch bản }\end{array}$ & \multicolumn{1}{c}{$\mathbf{0 7}$} \\
\hline 2020 & 3,142 & 3,142 & 3,142 & 3,142 & 3,142 & 3,142 & 3,142 \\
2025 & 3,619 & 3,648 & 3,051 & 3,442 & 3,169 & 3,278 & 3,591 \\
2030 & 4,154 & 4,215 & 2,923 & 3,757 & 3,382 & 3,408 & 4,091 \\
Tổng & $\mathbf{3 9 , 9 3 9}$ & $\mathbf{4 0 , 2 6 1}$ & $\mathbf{3 3 , 4 7 8}$ & $\mathbf{3 7 , 8 9 5}$ & $\mathbf{3 5 , 4 5 9}$ & $\mathbf{3 6 , 0 4 6}$ & $\mathbf{3 9 , 6 0 4}$ \\
\hline
\end{tabular}

Bảng 2. Lượng phát thải khí nhà kính theo các kịch bản giảm phát thải khí nhà kính trong lĩnh vực giao thông vận tải hành khách tại thành phố Hồ Chí Minh (triệu tấn CO2tđ).

\begin{tabular}{cccccccc}
\hline \multirow{2}{*}{ Năm } & $\begin{array}{c}\text { Kịch bản } \\
\mathbf{0 1}\end{array}$ & $\begin{array}{c}\text { Kịch bản } \\
\mathbf{0 2}\end{array}$ & $\begin{array}{c}\text { Kịch bản } \\
\mathbf{0 3}\end{array}$ & $\begin{array}{c}\text { Kịch bản } \\
\mathbf{0 4}\end{array}$ & $\begin{array}{c}\text { Kịch bản } \\
\mathbf{0 5}\end{array}$ & $\begin{array}{c}\text { Kịch bản } \\
\mathbf{0 6}\end{array}$ & $\begin{array}{c}\text { Kịch bản } \\
\mathbf{0 7}\end{array}$ \\
\hline 2020 & 2,143 & 2,143 & 2,143 & 2,143 & 2,143 & 2,143 & 2,143
\end{tabular}




\begin{tabular}{cccccccc}
\hline \multirow{2}{*}{ Năm } & $\begin{array}{c}\text { Kịch bản } \\
\text { 01 }\end{array}$ & $\begin{array}{c}\text { Kịch bản } \\
\mathbf{0 2}\end{array}$ & $\begin{array}{c}\text { Kịch bản } \\
\mathbf{0 3}\end{array}$ & $\begin{array}{c}\text { Kịch bản } \\
\mathbf{0 4}\end{array}$ & $\begin{array}{c}\text { Kịch bản } \\
\mathbf{0 5}\end{array}$ & $\begin{array}{c}\text { Kịch bản } \\
\mathbf{0 6}\end{array}$ & \multicolumn{1}{c}{ Kịch bản } \\
$\mathbf{0}$ & 2,444 & 2,550 & 2,342 & 2,324 & 2,148 & 2,213 & 2,443 \\
\hline 2025 & 2,785 & 3,023 & 2,557 & 2,519 & 2,291 & 2,285 & 2,757 \\
\hline TỔNG & $\mathbf{2 6 , 9 7 0}$ & $\mathbf{2 8 , 1 9 1}$ & $\mathbf{2 5 , 7 9 7}$ & $\mathbf{2 5 , 5 9 4}$ & $\mathbf{2 4 , 0 5 5}$ & $\mathbf{2 4 , 3 4 9}$ & $\mathbf{2 6 , 9 1 6}$ \\
\hline
\end{tabular}

Để thấy rõ hiệu quả của việc giảm phát thải khí nhà kính, chúng ta sẽ tính toán tiềm năng giảm phát thải khí nhà kính của các loại phương tiện vận tải hành khách theo các kịch bản (Bảng 3, bảng 4)

Bảng 3. Tiềm năng giảm phát thải khí nhà kính theo các kịch bản giảm phát thải khí nhà kính trong lĩnh vực giao thông vận tải hành khách tại Thủ đô Hà Nội (triệu tấn $\mathrm{CO}_{2}$ tđ).

\begin{tabular}{crrrrrr}
\hline Năm & Kịch bản 02 & Kịch bản 03 & Kịch bản 04 & Kịch bản 05 & Kịch bản 06 & Kịch bản 07 \\
\hline 2021 & $-0,01$ & 0,11 & 0,03 & 0,08 & 0,06 & 0,01 \\
2025 & $-0,03$ & 0,57 & 0,18 & 0,45 & 0,34 & 0,03 \\
2030 & $-0,06$ & 1,23 & 0,40 & 0,77 & 0,75 & 0,06 \\
TỔNG & $-\mathbf{0 , 3 2}$ & $\mathbf{6 , 4 6}$ & $\mathbf{2 , 0 4}$ & $\mathbf{4 , 4 8}$ & $\mathbf{3 , 8 9}$ & $\mathbf{0 , 3 3}$ \\
\hline
\end{tabular}

Bảng 4. Tiềm năng giảm phát thải khí nhà kính theo các kịch bản giảm phát thải khí nhà kính trong lĩnh vực giao thông vận tải hành khách tại thành phố Hồ Chí Minh (triệu tấn $\mathrm{CO}_{2}$ tđ).

\begin{tabular}{crrrrrr}
\hline Năm & Kịch bản 02 & Kịch bản 03 & Kịch bản 04 & Kịch bản 05 & Kịch bản 06 & Kịch bản 07 \\
\hline 2021 & $-0,02$ & 0,02 & 0,02 & 0,06 & 0,04 & $-0,01$ \\
2025 & $-0,11$ & 0,10 & 0,12 & 0,30 & 0,23 & 0,00 \\
2030 & $-0,24$ & 0,23 & 0,27 & 0,49 & 0,50 & 0,03 \\
TỐNG & $\mathbf{- 1 , 2 2}$ & $\mathbf{1 , 1 7}$ & $\mathbf{1 , 3 8}$ & $\mathbf{2 , 9 1}$ & $\mathbf{2 , 6 2}$ & $\mathbf{0 , 0 5}$ \\
\hline
\end{tabular}

3.2. Lương giá đồng lợi ích bán tín chỉ các-bon cho các kịch bản giảm phát thải khí nhà kính trong lĩnh vục giao thông vận tải hành khách tại Thủ đô Hà Nội và thành phố Hồ Chí Minh

Nghiên cứu sử dụng chỉ số Thị trường các-bon toàn cầu (IHS) để xác định giá trị trung bình của một tín chỉ các-bon là 21,28 USD (tương đương 498.859,40 VNĐ) tại thời điểm tháng 8/2020 [10]. Việc tính toán giá trị đồng lợi ích bán tín chỉ các-bon sẽ được thực hiện cho từng năm, sau đó quy đổi về giá trị hiện tại ròng tại năm 2020 (Bảng 5, Bảng 6).

Bảng 5. Giá trị đồng lợi ích bán tín chỉ các-bon cho các kịch bản giảm phát thải khí nhà kính trong lĩnh vực giao thông vận tải hành khách tại Thủ đô Hà Nội (Tỷ VNĐ).

\begin{tabular}{rrrrrrr}
\hline Năm & Kịch bản 02 & Kịch bản 03 & Kịch bản 04 & Kịch bản 05 & Kịch bản 06 & Kịch bản 07 \\
\hline 2021 & $-2,65$ & 53,30 & 16,13 & 41,16 & 31,62 & 5,51 \\
2022 & $-5,39$ & 108,29 & 33,02 & 83,29 & 64,44 & 7,21 \\
2023 & $-8,21$ & 165,00 & 50,70 & 126,39 & 98,46 & 9,20 \\
2024 & $-11,12$ & 223,48 & 69,18 & 170,48 & 133,71 & 11,48 \\
2025 & $-14,12$ & 283,76 & 88,49 & 224,85 & 170,21 & 14,05 \\
2026 & $-17,21$ & 345,90 & 108,64 & 254,35 & 207,99 & 16,92 \\
2027 & $-20,39$ & 409,93 & 129,66 & 284,78 & 247,06 & 20,10 \\
2028 & $-23,68$ & 475,90 & 151,57 & 316,17 & 287,45 & 23,59
\end{tabular}




\begin{tabular}{crrrrrr}
\hline Năm & Kịch bản 02 & Kịch bản 03 & Kịch bản 04 & Kịch bản 05 & Kịch bản 06 & Kịch bản 07 \\
\hline 2029 & $-27,06$ & 543,86 & 174,39 & 348,53 & 329,18 & 27,40 \\
2030 & $-30,54$ & 613,84 & 198,14 & 385,06 & 372,28 & 31,53 \\
\hline $\begin{array}{c}\text { NPV năm } \\
\mathbf{2 0 2 0}\end{array}$ & $\mathbf{- 7 6 , 2 4}$ & $\mathbf{3 . 2 2 3 , 2 5}$ & $\mathbf{4 8 2 , 8 8}$ & $\mathbf{1 . 0 8 2 , 5 0}$ & $\mathbf{9 2 2 , 1 8}$ & $\mathbf{8 0 , 9 9}$ \\
\hline
\end{tabular}

Bảng 6. Giá trị đồng lợi ích bán tín chỉ các-bon cho các kịch bản giảm phát thải khí nhà kính trong lĩnh vực giao thông vận tải hành khách tại thành phố Hồ Chí Minh (Tỷ VNĐ).

\begin{tabular}{crrrrrr}
\hline Năm & Kịch bản 02 & Kịch bản 03 & Kịch bản 04 & Kịch bản 05 & Kịch bản 06 & Kịch bản 07 \\
\hline 2021 & $-9,66$ & 9,28 & 10,98 & 27,52 & 21,52 & $-5,22$ \\
2022 & $-19,76$ & 18,98 & 22,42 & 55,48 & 43,75 & $-4,18$ \\
2023 & $-30,32$ & 29,12 & 34,35 & 83,89 & 66,72 & $-2,89$ \\
2024 & $-41,34$ & 39,72 & 46,79 & 112,74 & 90,43 & $-1,34$ \\
2025 & $-52,86$ & 50,78 & 59,74 & 147,45 & 114,91 & 0,49 \\
2026 & $-64,88$ & 62,33 & 73,23 & 165,99 & 140,19 & 2,59 \\
2027 & $-77,43$ & 74,38 & 87,27 & 185,04 & 166,28 & 5,00 \\
2028 & $-90,51$ & 86,95 & 101,87 & 204,59 & 193,20 & 7,70 \\
2029 & $-104,15$ & 100,05 & 117,07 & 224,66 & 220,97 & 10,72 \\
2030 & $-118,36$ & 113,71 & 132,86 & 246,74 & 249,63 & 14,07 \\
NPV năm & $\mathbf{- 2 8 8 , 4 8}$ & $\mathbf{2 7 7 , 1 4}$ & $\mathbf{3 2 5 , 3 5}$ & $\mathbf{7 0 6 , 3 1}$ & $\mathbf{6 2 1 , 3 7}$ & $\mathbf{6 , 0 1}$ \\
$\mathbf{2 0 2 0}$ & & & & & & \\
\hline
\end{tabular}

3.3. Lương giá đồng lợi ich tiết kiệm năng lượng cho các kịch bản giảm phát thải khí nhà kính trong lĩnh vục giao thông vận tải hành khách tại Thủ đô Hà Nội và thành phố Hồ Chí Minh

Giá bán các loại nhiên liệu sử dụng trong lĩnh vực giao thông vận tải hành khách công cộng tham gia vào tính toán được tổng hợp từ công bố chính thức của Tập đoàn Điện lực Việt Nam [11] và Tập đoàn Xăng dầu Việt Nam tại thời điểm ngày 8/6/2020 [12]:

- Xăng: $13.220 \mathrm{VNĐ/L;}$

- Dầu diesel: $11.040 \mathrm{VNĐ/L;}$

- Điện (cho thương mại - dịch vụ - sinh hoạt): 2.528 VNĐ/kWh;

Kết quả lượng giá đồng lợi ích tiết kiệm năng lượng cho các kịch bản giảm phát thải khí nhà kính trong lĩnh vực giao thông vận tải hành khách tại Thủ đô Hà Nội và thành phố Hồ Chí Minh được trình bày trong bảng 7 , bảng 8 .

Bảng 7. Giá trị đồng lợi ích tiết kiệm năng lượng cho các kịch bản giảm phát thải khí nhà kính trong lĩnh vực giao thông vận tải hành khách tại Thủ đô Hà Nội (Tỷ VNĐ).

\begin{tabular}{rrrrrrr}
\hline Năm & Kịch bản 02 & Kịch bản 03 & Kịch bản 04 & Kịch bản 05 & Kịch bản 06 & Kịch bản 07 \\
\hline 2021 & 1,31 & 655,03 & 176 & 456,91 & 340,27 & 502,63 \\
2022 & 2,66 & $1.330,78$ & 359 & 923,77 & 690,19 & 516,26 \\
2023 & 4,05 & $2.027,74$ & 550 & $1.400,61$ & $1.049,93$ & 530,18 \\
2024 & 5,49 & $2.746,41$ & 749 & $1.887,59$ & $1.419,66$ & 544,42 \\
2025 & 6,97 & $3.487,30$ & 955 & $2.493,68$ & $1.799,55$ & 558,98 \\
2026 & 8,49 & $4.250,93$ & 1.170 & $2.817,88$ & $2.189,80$ & 573,86
\end{tabular}




\begin{tabular}{crrrrrr}
\hline Năm & Kịch bản 02 & Kịch bản 03 & Kịch bản 04 & Kịch bản 05 & Kịch bản 06 & Kịch bản 07 \\
\hline 2027 & 10,06 & $5.037,85$ & 1.392 & $3.151,97$ & $2.590,56$ & 589,07 \\
2028 & 11,68 & $5.848,59$ & 1.623 & $3.496,12$ & $3.002,05$ & 604,62 \\
\hline 2029 & 13,35 & $6.683,72$ & 1.863 & $3.850,55$ & $3.424,44$ & 620,52 \\
2030 & 15,07 & $7.543,79$ & 2.112 & $4.252,62$ & $3.857,92$ & 636,76 \\
$\begin{array}{c}\text { NPV năm } \\
\mathbf{2 0 2 0}\end{array}$ & $\mathbf{4 1 , 3 8}$ & $\mathbf{1 8 . 8 3 2 , 8 3}$ & $\mathbf{5 . 7 1 1 , 0 5}$ & $\mathbf{1 1 . 9 8 2 , 0 5}$ & $\mathbf{9 . 6 9 2 , 0 2}$ & $\mathbf{3 . 1 0 7 , 0 9}$ \\
\hline
\end{tabular}

Bảng 8. Giá trị đồng lợi ích tiết kiệm năng lượng cho các kịch bản giảm phát thải khí nhà kính trong lĩnh vực giao thông vận tải hành khách tại thành phố Hồ Chí Minh (Tỷ VNĐ).

\begin{tabular}{crrrrrr}
\hline Năm & Kịch bản 02 & Kịch bản 03 & Kịch bản 04 & Kịch bản 05 & Kịch bản 06 & Kịch bản 07 \\
\hline 2021 & 4.785 & $114.041,24$ & 118 & 304,14 & 231,71 & 287,96 \\
2022 & 9.789 & $233.293,67$ & 239 & 609,10 & 466,74 & 289,77 \\
2023 & 15.019 & $357.935,89$ & 363 & 914,80 & 705,14 & 291,51 \\
2024 & 20.483 & $488.151,94$ & 490 & $1.221,22$ & 946,94 & 293,18 \\
2025 & 26.189 & $624.131,45$ & 620 & $1.591,46$ & $1.192,18$ & 294,77 \\
2026 & 32.144 & $766.069,81$ & 753 & $1.778,84$ & $1.440,89$ & 296,29 \\
2027 & 38.359 & $914.168,33$ & 889 & $1.968,66$ & $1.693,11$ & 297,72 \\
2028 & 44.840 & $1.068 .634,41$ & 1.028 & $2.160,92$ & $1.948,88$ & 299,06 \\
2029 & 51.598 & $1.229 .681,70$ & 1.170 & $2.355,61$ & $2.208,23$ & 300,30 \\
2030 & 58.641 & $1.397 .530,30$ & 1.315 & $2.570,16$ & $2.471,20$ & 301,45 \\
NPV năm & & & & & & \\
$\mathbf{2 0 2 0}$ & $\mathbf{1 5 7 , 2 1}$ & $\mathbf{3 . 4 0 6 , 1 2}$ & $\mathbf{3 . 6 6 0 , 9 2}$ & $\mathbf{7 . 5 4 7 , 0 4}$ & $\mathbf{6 . 3 5 7 , 9 8}$ & $\mathbf{1 . 6 4 2 , 4 2}$ \\
\hline
\end{tabular}

3.4. Giá trị tổng 2 đồng lợi ích cho các kịch bản giảm phát thải khí nhà kính trong lĩnh vục giao thông vận tải hành khách tại Thủ đô Hà Nội và thành phố Hồ Chí Minh

Bảng 9. Giá trị tổng 2 đồng lợi ích cho các kịch bản giảm phát thải khí nhà kính trong lĩnh vực giao thông vận tải hành khách tại Thủ đô Hà Nội (Tỷ VNĐ).

\begin{tabular}{crrrrrr}
\hline \multicolumn{1}{c}{ Năm } & Kịch bản 02 & Kịch bản 03 & Kịch bản 04 & Kịch bản 05 & Kịch bản 06 & Kịch bản 07 \\
\hline $\begin{array}{c}\text { Đồng lợi ích bán } \\
\text { tín chỉ các-bon }\end{array}$ & $-76,24$ & $3.223,25$ & 482,88 & $1.082,50$ & 922,18 & 80,99 \\
$\begin{array}{c}\text { Đồng lợi ích tiết } \\
\text { kiệm năng lượng } \\
\text { Tổng }\end{array}$ & 41,38 & $18.832,83$ & $5.711,05$ & $11.982,05$ & $9.692,02$ & $3.107,09$ \\
\hline
\end{tabular}

Bảng 10. Giá trị tổng 2 đồng lợi ích cho các kịch bản giảm phát thải khí nhà kính trong lĩnh vực giao thông vận tải hành khách tại thành phố Hồ Chí Minh (Tỷ VNĐ).

\begin{tabular}{crrrrrr}
\hline Năm & Kịch bản 02 & Kịch bản 03 & Kịch bản 04 & Kịch bản 05 & Kịch bản 06 & Kịch bản 07 \\
\hline $\begin{array}{c}\text { Đồng lợi ích bán } \\
\text { tín chỉ các-bon }\end{array}$ & $-288,48$ & 277,14 & 325,35 & 706,31 & 621,37 & 6,01 \\
$\begin{array}{c}\text { Đồng lợi ích tiết } \\
\text { kiệm năng lượng } \\
\text { Tổng }\end{array}$ & 157,21 & $3.406,12$ & 9.648 & $10.902,89$ & $10.803,93$ & $8.634,18$ \\
\hline
\end{tabular}


Giá trị tổng 2 đồng lợi ích (bán tín chỉ các-bon và tiết kiệm năng lượng) của các kịch bản giảm phát thải khí nhà kính trong lĩnh vực giao thông vận tải hành khách tại Thủ đô Hà Nội và thành phố Hồ Chí Minh trong giai đoạn 2020 - 2030 là những con số rất đáng kể. Giá trị cực đại của 2 đồng lợi ích đạt đến con số 22.056,08 tỷ VNĐ ở Thủ đô Hà Nội theo kịch bản 03 và 11.609,20 tỷ VNĐ ở thành phố Hồ Chí Minh theo kịch bản 05 .

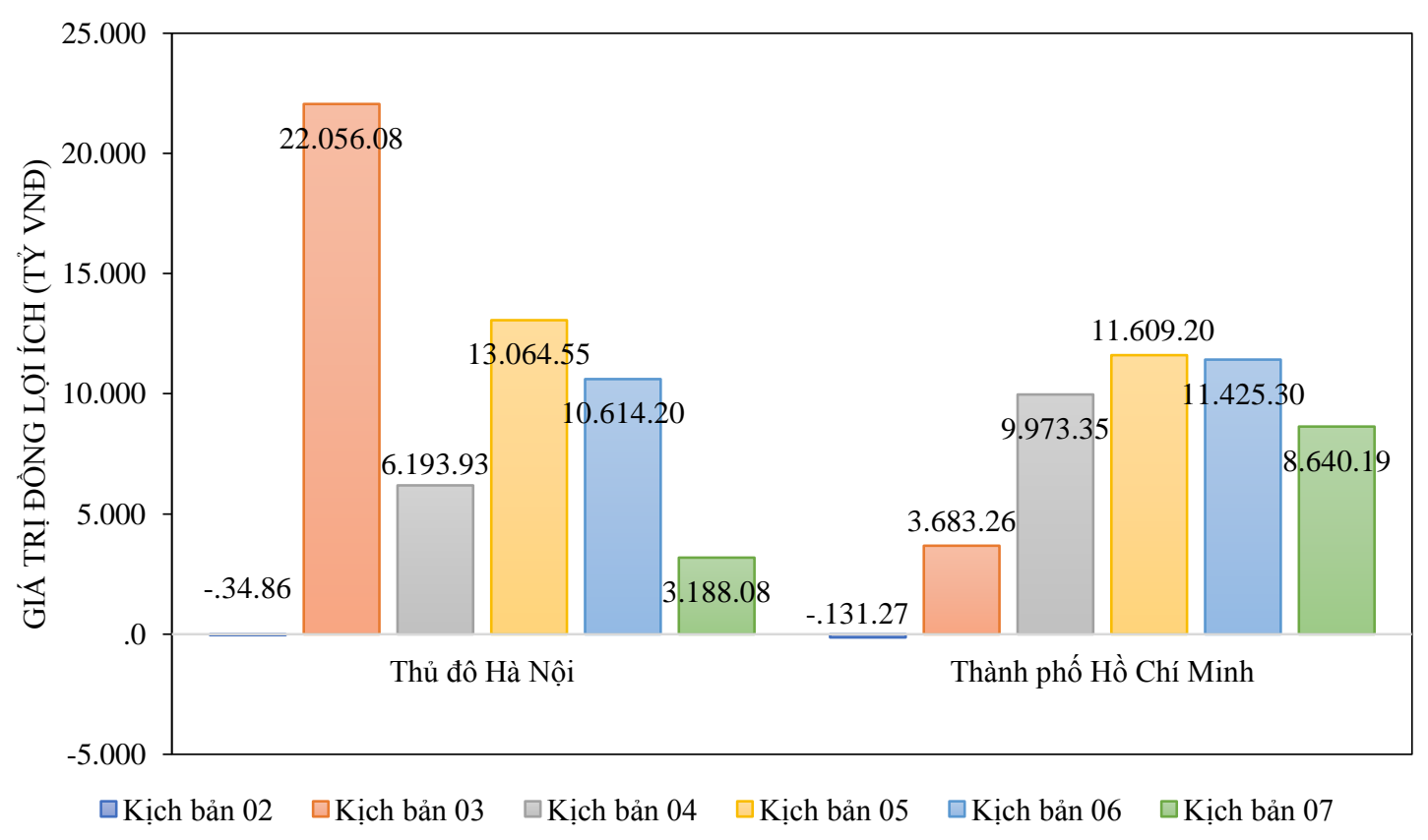

Hình 1. Giá trị tổng 2 đồng lợi ích cho các kịch bản giảm phát thải khí nhà kính trong lĩnh vực giao thông vận tải hành khách tại Thủ đô Hà Nội và thành phố Hồ Chí Minh.

\section{Kết luận}

Việc tính toán 2 đồng lợi ích của các giải pháp giảm phát thải khí nhà kính trong lĩnh vực giao thông vận tải hành khách của Thủ đô Hà Nội và thành phố Hồ Chí Minh cho phép đi đến một số kết quả như sau:

1. Theo kết quả tại bảng 9 và bảng 10 , giá trị tổng 2 đồng lợi ích (bán tín chỉ các-bon và tiết kiệm năng lượng) của các kịch bản giảm phát thải khí nhà kính trong lĩnh vực giao thông vận tải hành khách tại Thủ đô Hà Nội và thành phố Hồ Chí Minh trong giai đoạn 2020 - 2030 là những con số rất đáng kể. Giá trị cực đại của 2 đồng lợi ích đạt đến con số 22.056,08 tỷ VNĐ ở Thủ đô Hà Nội theo kịch bản 03 và 11.609,20 tỷ VNĐ ở thành phố Hồ Chí Minh theo kịch bản 05 .

2. Theo kịch bản 02 , cả ở Thủ đô Hà Nội và thành phố Hồ Chí Minh, giá trị tổng 2 đồng lợi ích nhận được đều là những số âm $(-34,86$ tỷ $\mathrm{VNĐ} \mathrm{và}-131,27$ tỷ $\mathrm{VNĐ)}$. Điều này nói lên rằng, theo kịch bản này sẽ không đạt được mục tiêu giảm phát thải khí nhà kính so với kịch bản cơ sở và kéo theo không đạt được lợi ích kinh tế. Tuy nhiên, chúng ta sẽ không loại trừ kịch bản này. Trong giao thông vận tải hành khách đô thị tại Thủ đô Hà Nội và thành phố Hồ Chí Minh, việc giảm số lượng xe máy là bắt buộc phải thực hiện để đạt được mục tiêu giảm chiếm dụng mặt đường giao thông-nguyên nhân chủ yếu gây ra nạn ùn tắc, kẹt xe. Muốn đạt được đồng thời mục tiêu giảm chiếm dụng mặt đường giao thông và giảm phát thải khí nhà kính, cần phải giảm nhiều hơn tỷ lệ đảm nhận phương tiện của xe máy so với kịch bản 02 đã đề xuất.

3. Từ 7 kịch bản đã xem xét ở trên, các nhà quản lý có thể lựa chọn sự kết hợp khác nhau tạo thành những tổ hợp giải pháp giảm phát thải khí nhà kính trong lĩnh vực giao thông vận 
tải hành khách của Thủ đô Hà Nội và thành phố Hồ Chí Minh để thực thi trong thực tế nhằm đạt được mục tiêu kép: giảm thiểu phát thải khí nhà kính và tăng giá trị tổng của 2 đồng lợi ích.

Đóng góp của tác giả: Xây dựng ý tưởng nghiên cứu: T.D.B.T, L.Q.H., T.D.T.M.; Lựa chọn phương pháp nghiên cứu: T.D.B.T., L.Q.H.; Viết bản thảo bài báo: T.D.T.M.; Chỉnh sửa bài báo: T.D.B.T.

Lời cảm ơn: Nghiên cứu này được thực hiện dưới sự tài trợ của đề tài nghiên cứu khoa học và công nghệ cấp Bộ "Phân tích kinh tế định lượng các giải pháp ứng phó với biến đổi khí hậu của Việt Nam", mã số TNMT.2017.05.20.

Lời cam đoan: Tập thể tác giả cam đoan bài báo này là công trình nghiên cứu của tập thể tác giả, chưa được công bố ở đâu, không được sao chép từ những nghiên cứu trước đây; không có sự tranh chấp lợi ích trong nhóm tác giả.

\section{Tài liệu tham khảo}

1. UNFCCC. Decision 1/CP.21 on Adoption of the Paris Agreement, vol. FCCC/CP/20. Paris: UNFCCC, Conference of Parties (COP 21), 2015.

2. IPCC. Climate Change 2014: Mitigation of Climate Change. Contribution of Working Group III to the Fifth Assessment Report of the Intergovernmental Panel on Climate Change. Cambridge and New York: Cambridge University Press, 2014.

3. Phương, T.; Anh, Đ.T. Báo cáo tổng kết đề tài khoa học và công nghệ cấp Bộ "Nghiên cứu hiệu quả kinh tế trong giảm nhẹ khí nhà kính cho lĩnh vực quản lý chất thải”, 2017.

4. Thắng, Đ.N. Báo cáo tổng kết đề tài khoa học và công nghệ cấp nhà nước "Nghiên cứu, đánh giá tiềm năng lợi ích kép về môi trường của các hoạt động ứng phó với biến đổi khí hậu ở Việt Nam", 2014.

5. Dixon, J.A.; Hufschmidt, M.M. Economic Valuation Techniques for the Environment: A Case Study Workbook. Johns Hopkins University Press, Baltimore, 1986.

6. Markandya, A.; Pearce, D.W. Environmental considerations and the choice of discount rate, Environment Department Working paper no. 3 (World Bank, Washington DC), 1988.

7. Munasinghe, M. Environmental issues and economic decisions in developing countries. World Dev. 1993, 21, 1729-1748. https://doi.org/10.1016/0305-750X(93)90080-S.

8. Tổng công ty tư vấn thiết kế giao thông vận tải (TEDI). Quy hoạch giao thông vận tải Thủ đô Hà Nội đến năm 2030, tầm nhìn đến năm 2050, 2016.

9. Công ty Cổ phần Tư vấn Thiết kế giao thông vận tải phía Nam (TEDI South), Điều chỉnh Quy hoạch phát triển giao thông vận tải thành phố Hồ Chí Minh đến năm 2020 và tầm nhìn sau năm 2020, 2013.

10. IHS Markit Global Carbon Index (USD), https://indices.ihsmarkit.com/Carbonindex, 2020.

11. Tập đoàn Điện lực Việt Nam, Biểu giá bán điện, https://www.evn.com.vn/c3/evn-va-khach-hang/Bieu-gia-ban-dien-9-76.aspx, 2020.

12. Tập đoàn Xăng dầu Việt Nam, Giá bán lẻ xăng dầu, https://www.petrolimex.com.vn/, 2020. 


\title{
Evaluation of co-benefits for passenger transport sector based on
} the transportation planning of Ho Chi Minh City by 2020, with a vision after 2020

\author{
Tran Do Bao Trung ${ }^{1 *}$, Luong Quang Huy ${ }^{1}$, Tran Do Tra My ${ }^{2}$ \\ ${ }^{1}$ Department of Climate Change, Ministry of Natural Resources and Environment; \\ tdbtrung@monre.gov.vn; huylq98@gmail.com \\ ${ }^{2}$ Vietnam Environment Protection Fund, Ministry of Natural Resources and Environment; \\ mytranvepf@gmail.com
}

\begin{abstract}
In this study, we apply the co-benefit evaluation method to calculate the value of 2 co-benefits: energy saving and sale of carbon credit for greenhouse gases mitigation scenarios in the passenger transport sector based on the date of the transportation development planning of Hanoi and Ho Chi Minh city. The evaluations considered 7 different scenarios. The achieved results provided monetary valuation for each greenhouse gases mitigation scenarios in terms of enery saving, sale of carbon credit. In which, the net present value in 2020 of the 2 co-benefit will reach 22,056.08 billion VND in Hanoi under scenario 03 and 11,609.20 billion VND in Ho Chi Minh city under scenario 05.
\end{abstract}

Keywords: Co-benefits; Greenhouse gases emissions; Passenger transport; Hanoi; Ho Chi Minh City. 